\title{
Intensely clustered outbreak of visceral leishmaniasis (kala-azar) in a setting of seasonal migration in a village of Bihar, India
}

\author{
Arvind Kumar $^{1}$, Suman Saurabh ${ }^{2 *}$, Sarosh Jamil ${ }^{3}$ and Vijay Kumar ${ }^{4}$
}

\begin{abstract}
Background: A visceral leishmaniasis outbreak was reported from a village in a low-endemic district of Bihar, India. Methods: Outbreak investigation with house-to-house search and rapid test of kala-azar suspects and contacts was carried out. Sandfly collection and cone bio-assay was done as part of entomological study.

Results: A spatially and temporally clustered kala-azar outbreak was found at Kosra village in Sheikhpura district with 70 cases reported till December 2018. Delay of more than a year was found between diagnosis and treatment of the index case. The southern hamlet with socio-economically disadvantaged migrant population was several times more affected than rest of the village (attack rate of $19.0 \%$ vs $0.5 \%$ respectively, $\mathrm{OR}_{\mathrm{MH}}=39.2,95 \% \mathrm{Cl} 18.2-$ 84.4). The median durations between onset of fever to first contact with any health services, onset to kala-azar diagnosis, diagnosis to treatment were 10 days (IQR 4-18), 30 days (IQR 17-73) and 1 day (IQR 0.5 to 3), respectively, for 50 kala-azar cases assessed till June 2017. Three-fourths of these kala-azar cases had out-of-pocket medical expenditure for their condition. Known risk factors for kala-azar such as illiteracy, poverty, belonging to socially disadvantaged community, migration, residing in kutcha houses, sleeping in rooms with unplastered walls and nonuse of mosquito nets were present in majority of these cases. Only half the dwellings of the kala-azar cases were fully sprayed. Fully gravid female $P$. argentipes collected post indoor residual spraying (IRS) and low sandfly mortality on cone-bioassay indicated poor effectiveness of vector control.
\end{abstract}

Conclusions: There is need to focus on low-endemic areas of kala-azar. The elimination programme should implement a routine framework for kala-azar outbreak response. Complete case-finding, use of quality-compliant insecticide and coverage of all sprayable surfaces in IRS could help interrupt transmission during outbreaks.

Keywords: Kala-azar, Visceral leishmaniasis, Outbreak, Epidemic, Migration, Indoor residual spraying, India

\section{Background}

Visceral leishmaniasis (kala-azar) is a disease caused by Leishmania donovani, a protozoal parasite and is transmitted to humans through the bite of Phlebotomus argentipes sandfly [1]. Owing to presence of only human reservoir and high cure rates of kala-azar in the Indian

\footnotetext{
* Correspondence: drsumansaurabh@gmail.com;

saurabhs@aiimsjodhpur.edu.in

${ }^{2}$ Zonal Coordinator - Neglected Tropical Diseases, Muzaffarpur, World Health Organization - India. Currently, Assistant Professor, Department of

Community and Family Medicine, All India Institute of Medical Sciences

(AlIMS) - Jodhpur, Jodhpur, Rajasthan 342005, India

Full list of author information is available at the end of the article
}

sub-continent (Bangladesh, India and Nepal), kala-azar has been targeted for elimination as a public health problem [2]. India has already achieved a remarkable ten-fold reduction in annual kala-azar cases from 2007 to 2018 [3, 4]. A target of reduction of annual incidence below 1 per 10,000 population at sub-district (block) level by 2020 has been adopted for elimination in India $[2,5]$.

Kala-azar has a long history of outbreaks with the earliest recorded outbreak in 1824-25 in Jessore district of present day Bangladesh [6, 7]. It also shows a cyclical trend every 15-20 years $[6,7]$. Outbreaks of kala-azar in

(c) The Author(s). 2020 Open Access This article is distributed under the terms of the Creative Commons Attribution 4.0 International License (http://creativecommons.org/licenses/by/4.0/), which permits unrestricted use, distribution, and 
previously non-endemic areas have also been reported [8-10]. Therefore, to sustainably achieve the goal of elimination, attention is also needed on blocks with kala-azar incidence below the elimination target. Consequently, Accelerated Plan for Kala-azar Elimination was launched in February 2017 emphasizing enhanced surveillance in borderline and low-endemic blocks with annual incidence of $0.8-1$ and less than 0.8 per 10,000 population, respectively [11].

A kala-azar outbreak was reported by the Bihar state government in March 2017 at Kosra village in Sheikhpura district. This district lies in the fringe of the kala-azar endemic zone in India (Fig. 1). With annual kala-azar incidence of 0.19 per 10,000 population in 2016, it ranked 22nd among the 33 endemic districts of Bihar. The affected village is in Sheikhpura Sadar block, $12 \mathrm{~km}$ from the district headquarters. It borders Sekhopur Sarai block of Sheikhpura district and Warsaliganj block of Nawada district (Fig. 1).

Sheikhpura Sadar block and neighbouring Sekhopur Sarai block were low-endemic and had reported kala- azar cases sporadically from 2013 to 2016 (Fig 2). Neighbouring Warsaliganj block had not reported any kalaazar case during this period. As per the official line list available since January 2011, the affected village had not reported any case of kala-azar until the onset of the present outbreak. Kala-azar line list prior to 2011 was not available in the district and sporadic cases used to directly get treated in the private sector and were not notified to the government.

\section{Methods}

\section{Study design and planning}

The outbreak response consisted of door-to-door case search, enumeration of the affected population and entomological assessment of effectiveness of vector control activities. An outbreak response team led by the District Vector Borne Disease Control Officer (DVBDCO) was constituted in June 2017. The team consisted of medical officers, a lab technician and frontline health workers associated with the primary health centre. Since the study

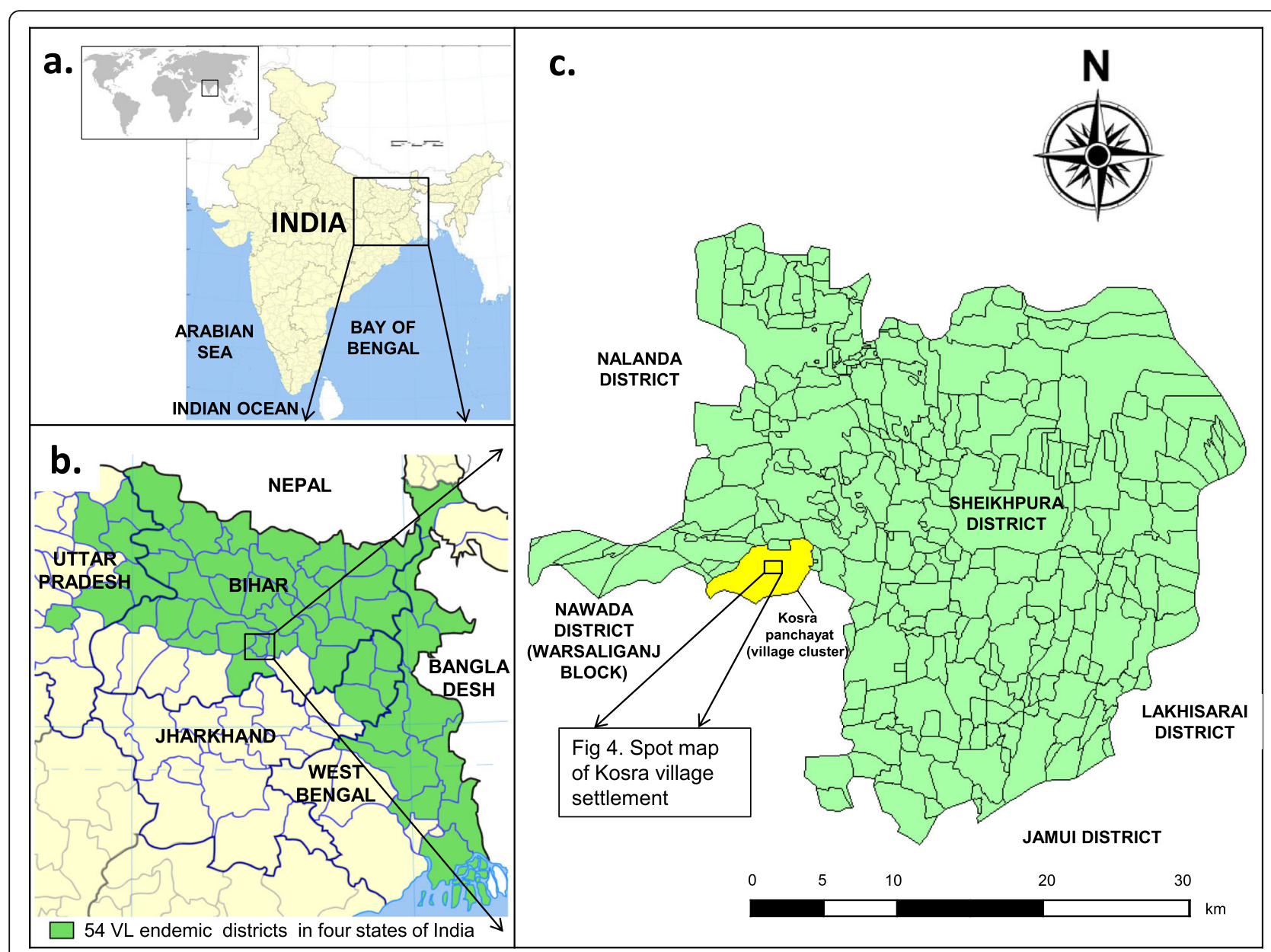

Fig. 1 Location of the outbreak in Sheikhpura, Bihar, India - a) location of kala-azar endemic area in the eastern part of India b) location of Sheikhpura district among the kala-azar endemic districts in India c) location of the affected village within Sheikhpura district. (Modified from source file - https://commons.wikimedia.org/wiki/File:India_districts_map.svg, Creative Commons Attribution-Share Alike 4.0 International license) 


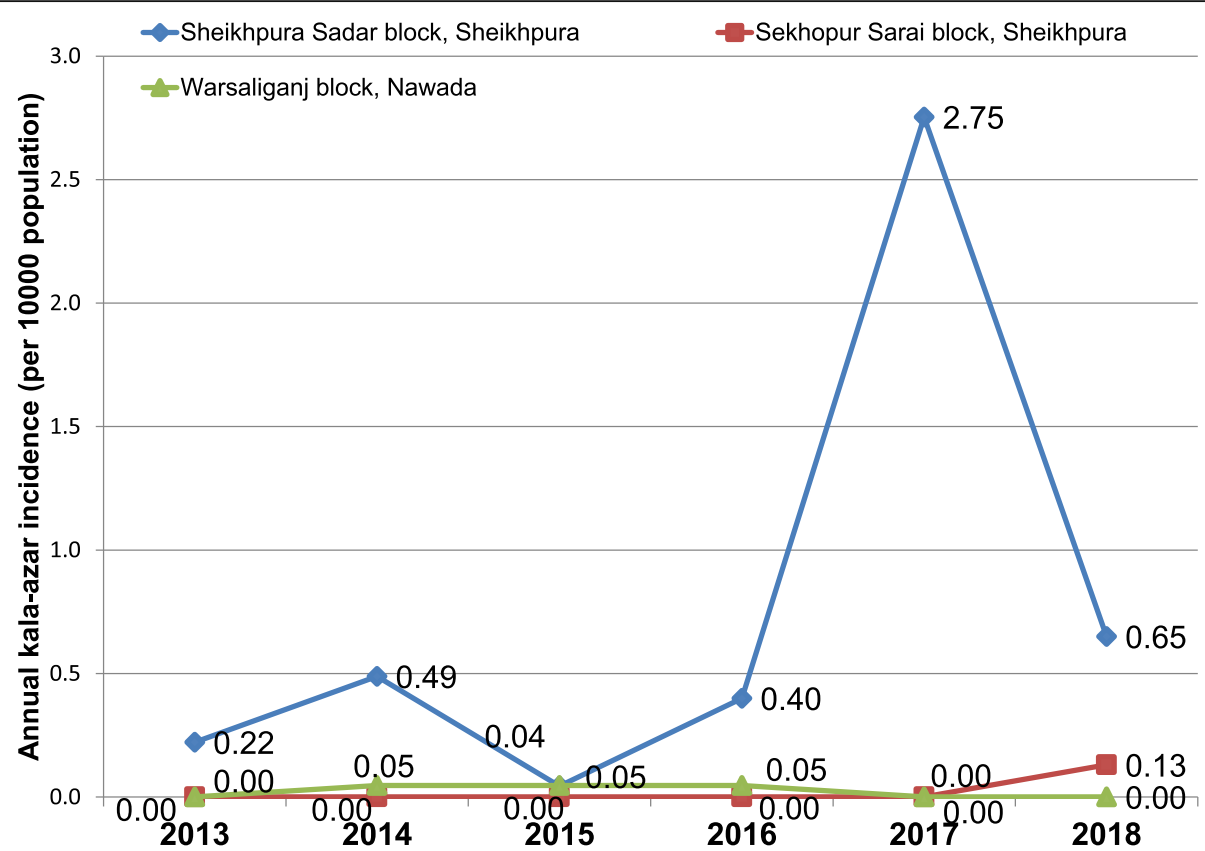

Fig. 2 Reporting of kala-azar cases from Sheikhpura sadar block, Sheikhpura Warsaliganj block, Nawada adjacent to Kosra village (2013-2018)Data source: District Vector Borne Disease Control Office, Sheikhpura, Bihar, India.

was within the purview of programme evaluation and was part of an urgent outbreak response, it was exempt from prior institutional ethics committee approval as per national guidelines [12]. Existing pulse polio supplementary immunization micro-plan was used to divide the village into 6 clusters of 50-60 households each. A team of frontline health workers and medical officers visited the households and completely enumerated the area.

During the household visit, those with fever and contacts of known kala-azar cases were referred for rK39 rapid test (Kala-azar Detect ${ }^{\mathrm{mix}}$, InBios Inc., Seattle, USA) at the health sub-centre located in the village. Those with history of an earlier episode of kala-azar were excluded from rk39 test. Contacts were defined as those who resided in the same household as known kala-azar cases and their next-door neighbours. All rK39-positives with history of two or more weeks of fever were invariably referred to the government district hospital. Here they were confirmed as having kalaazar clinically. Those with two or more weeks of fever and finding of palpable spleen were treated with $10 \mathrm{mg} / \mathrm{kg}$ single dose liposomal amphotericin B (LAmB), as per programme guidelines [4]. HIV test was done for all patients. Other locally endemic differential diagnoses such as typhoid and malaria were excluded through laboratory tests ordered based on clinician's judgement at district hospital. Since programme guidelines recommend parasitological confirmation only in specific situations at tertiary centres equipped with this facility, it was not attempted routinely for the patients referred to the district hospital [11].
A semi-structured questionnaire was developed for assessing kala-azar cases regarding awareness and access to treatment and preventive services. Known risk factors for kalaazar were also assessed among the cases. Interview of relatives of those who had died after prolonged fever was also done using the WHO Verbal Autopsy instrument 2016.

\section{Entomological study}

Entomological study was conducted by scientists from Rajendra Memorial Research Institute of Medical Sciences (RMRIMS), Patna, India. Vector density was assessed through sandfly collection using mouth aspirator and CDC light trap in randomly selected households in July 2017, two days after focal indoor residual spraying (IRS) was conducted in the most affected southern hamlet. Species identification was done using taxonomic key described by Lewis [13]. Cone bioassay was done on both mud and brick surfaces to provide estimate of insecticidal efficacy of IRS using WHO recommended procedures $[14,15]$.

\section{Data entry and analysis}

Data was entered and cross-checked for errors. Agewise, gender-wise and area of residence-wise attack rates were described using numerator of all kala-azar cases reported up to December 2018 (Fig. 3). The gender, age and month of fever onset and diagnosis of cases reported after the outbreak investigation in June 2017 were taken from the latest line list available in the district. The 


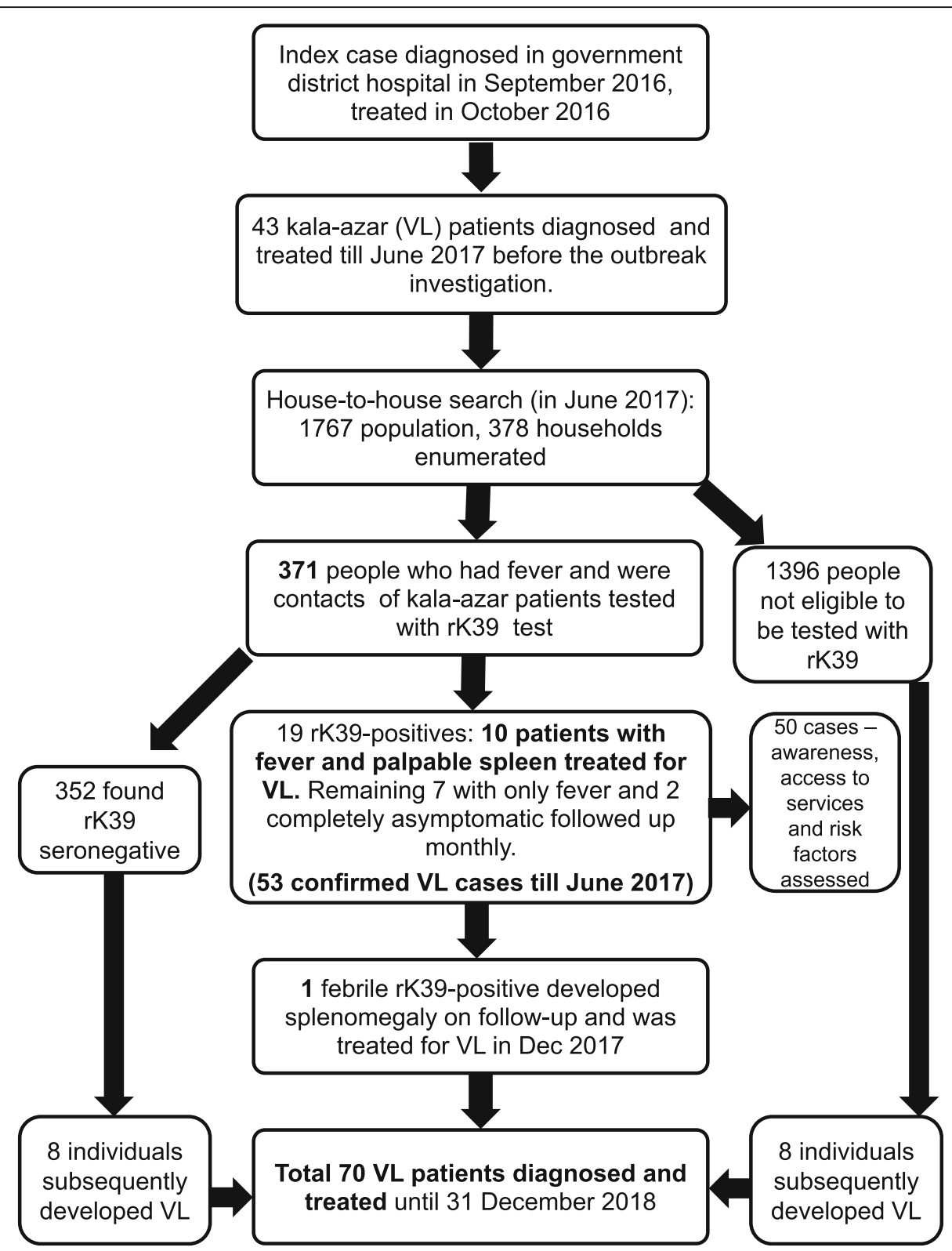

Fig. 3 Flowchart showing evolution of the kala-azar outbreak until December 2018

denominator was taken from the house to house enumeration conducted in June 2017.

Mantel-Haenszel method was used to statistically compare the attack rates of kala-azar for the most affected hamlet as compared to rest of the village, stratified by gender. The spot-map represented all kala-azar cases till December 2018 (Fig. 4). Nearest neighbour analysis of kala-azar cases was done with QGIS v3.2.3.

\section{Results}

During this outbreak investigation, 371 people with fever and contacts of kala-azar patients were tested (Fig. 3). Nineteen individuals were found to be rK39-positive among whom 10 with two or more weeks of fever and palpable spleen were treated at the district hospital. None of the patients were found HIV positive. Out of the remaining $9 \mathrm{rk39}$-sero-positive individuals without palpable spleen, 7 had fever while 2 were completely asymptomatic (Fig. 3). The index case was found to have developed fever as early as June 2015 and was finally diagnosed with kala-azar at the district hospital in September 2016 and was treated with LAmB in October 2016.

The outbreak was ongoing with a size of 70 cases detected till December 2018 (Fig. 3). Additionally, 4 kalaazar cases have been reported recently in the village, one each in February, March, May and September 2019. 


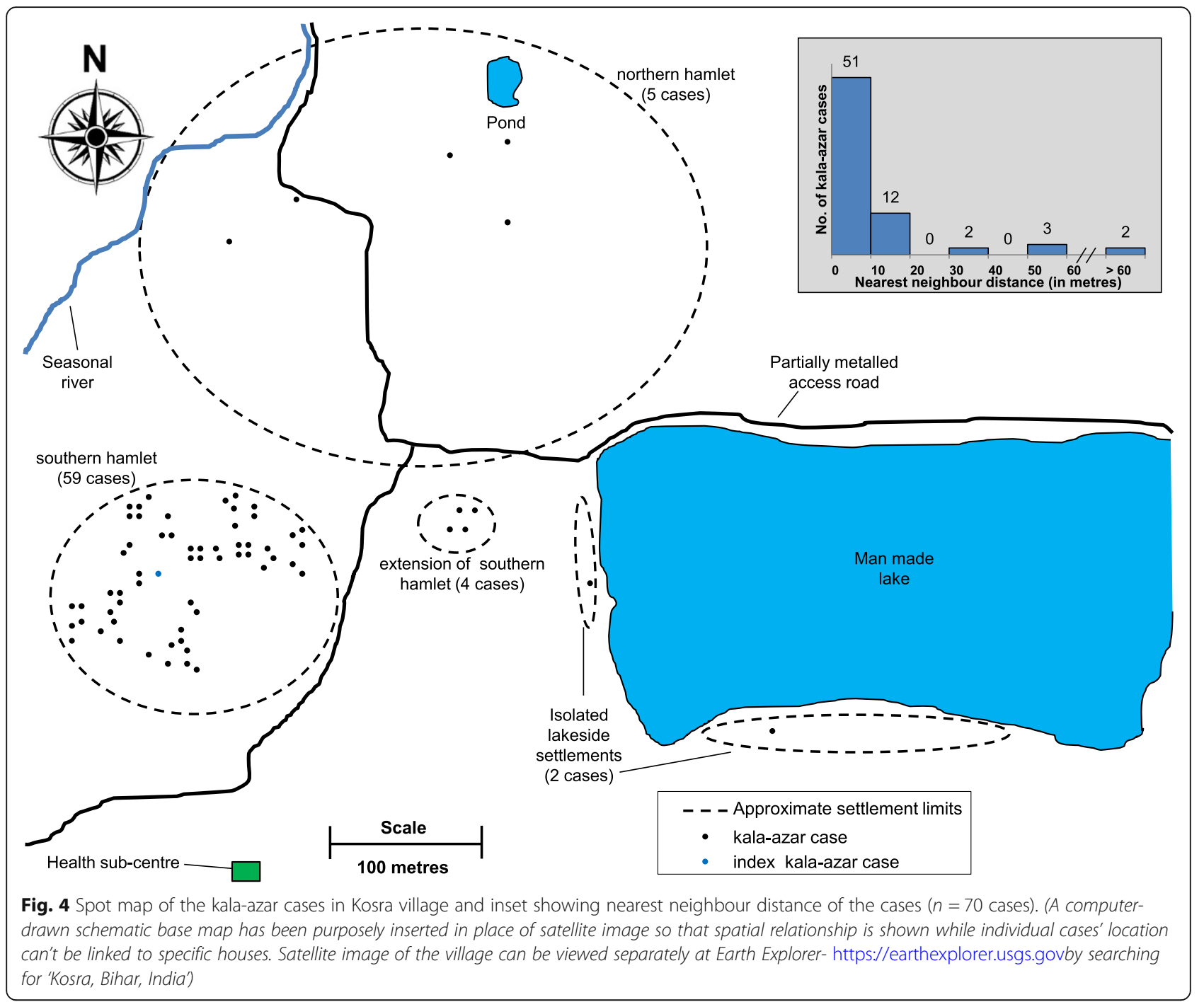

\section{Environmental characteristics}

The wet season lasts from mid-June to September. The eco-environmental conditions found here are considered suitable for sandfly breeding $[16,17]$. The settlement of Kosra village lies close to a man-made lake and a pond. A seasonal river is located to the west (Fig. 4). Water bodies and seasonal river banks have been geospatially associated with sandfly abundance [18].

\section{Description of population at risk and outbreak (70 kala- azar cases detected till December 2018)}

The enumerated population of the Kosra village was 1767 with $52.2 \%$ males. A total of 378 households were enumerated. The village is divided into mainly two settlements (Fig. 4). The smaller hamlet in the south and its extension is entirely populated by the socioeconomically disadvantaged mushahar community which is notified as a scheduled caste by the government. This hamlet has 72 households and a population of 341. The small isolated lakeside settlement comprises of 20 households and is inhabited by 110 people belonging to scheduled caste. The large northern hamlet has 286 households with a resident population of 1316, mainly comprising of population belonging to the relatively privileged castes.

Most kala-azar cases were clustered in the southern hamlet around the index case whereas sporadic cases were found in the rest of the village (Fig. 4). Distances from one patient to another nearest patient had a left-skewed distribution (Median $7.35 \mathrm{~m}$, interquartile range $6.39-10.36 \mathrm{~m}$ ). More than two-thirds of kala-azar cases were residing within $10 \mathrm{~m}$ of another kala-azar case (Fig. 4). Around three-fourths of all kala-azar cases developed fever during a span of six months i.e. from November 2016 to May 2017. The upsurge in cases being diagnosed was seen only in March 2017, owing mainly to the early return of migrants after developing fever at their seasonal migration sites (Fig. 5). Thus a spatial and temporal clustering of kala-azar cases was found in the village. 


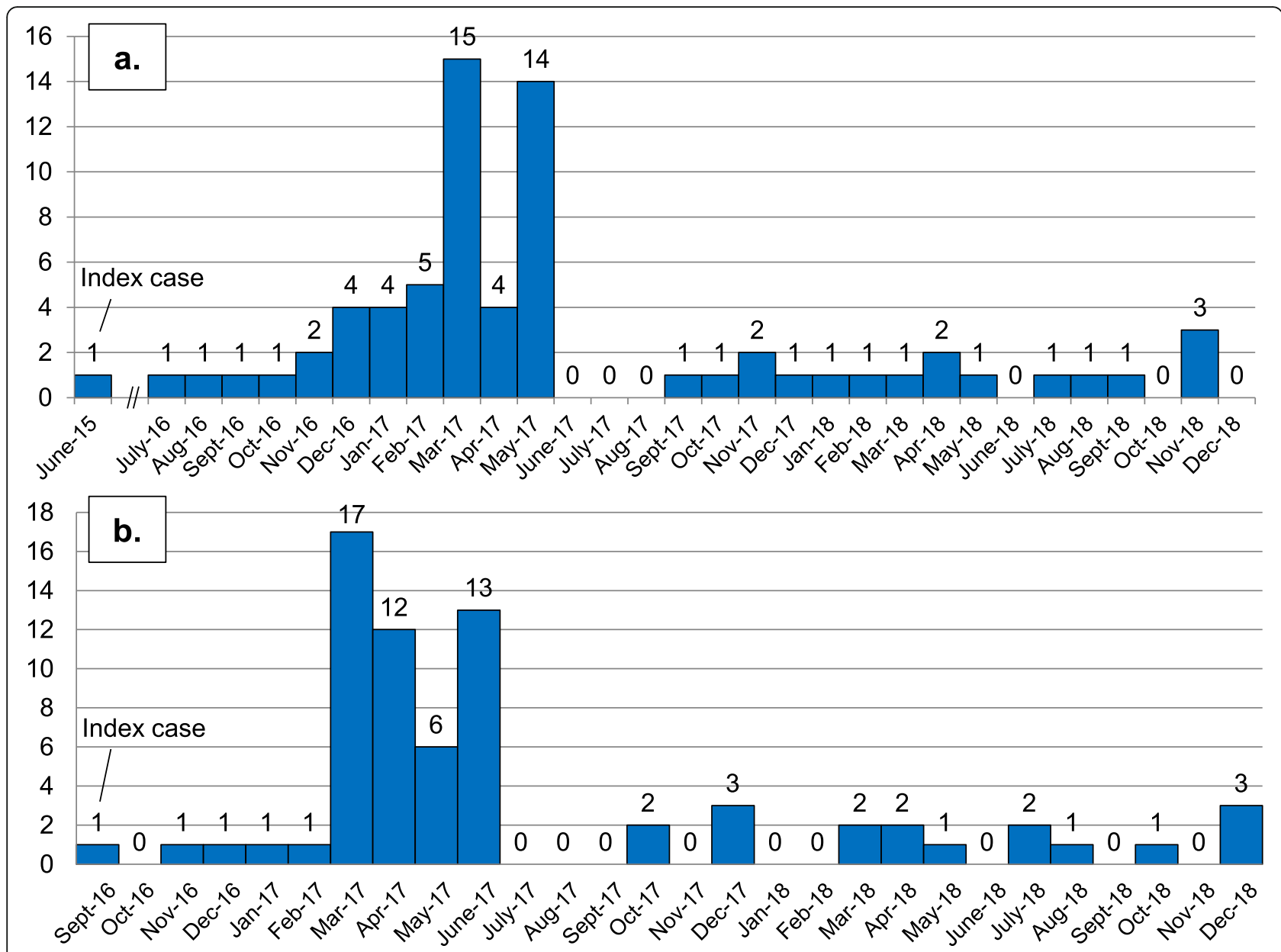

Fig. 5 Time distribution of kala-azar cases $(n=70)$ at Kosra village until December 2018 - a) by month of developing fever and $\mathbf{b})$ by month of being diagnosed for kala-azar

Around one-third of the 70 kala-azar cases diagnosed till December 2018 belonged to 0-14-year age group. Age-group wise attack rates were not significantly different (Table 1 ). Around $61.4 \%$ of them were males. Male gender was not found to be a significant risk factor for being affected with kala-azar (Risk ratio $=1.44,95 \%$ CI 0.90-2.31, $p=0.130$ ).

Kala-azar attack-rate in the southern hamlet and its extension was several times higher than in the rest of the village (19.0\% vs $0.5 \%)$. Mantel-Haenszel adjusted risk ratio for being affected by kala-azar for residents of southern hamlet was 39.2 (95\% CI 18.2-84.4, $p<0.0001)$ as compared to rest of the village, while taking gender as stratifying variable.

\section{Out of pocket expenditure, delay in diagnosis and} treatment, access to services and awareness of the cases Fifty kala-azar patients who could be interviewed out of the 53 reported till June 2017 were assessed for out of pocket expenditure, delay in diagnosis and treatment, access to services and awareness (Table 2). The median durations between onset of fever to first contact with any health services, onset to diagnosis, diagnosis to treatment were 10 days (IQR 4-18), 30 days (IQR 17-73) and 1 day (IQR 0.5 to 3$)$ respectively.

The median total out-of-pocket medical expenditure was Rs 2000 (IQR 0-5000) with the highest expenditure of Rs 50, 000 for the index case. Only in 12 of the 50 patients, the first health facility contact was with the government health system on their own or through active case search by frontline workers, with services availed completely free of cost (Table 2). Known risk factors for kala-azar such as illiteracy, poverty, belonging to socially disadvantaged community, migration, residing in kutcha houses and sleeping in rooms with unplastered walls and non-use of mosquito nets were present in majority of these cases (Table 2).

\section{The setting of seasonal migration}

Residents in the southern hamlet migrate seasonally for working in brick kilns located in northern and eastern part of India (Fig. 6). We observed lack of land ownership and poverty as the 'push factors' in prompting this migration $[19,20]$. The migrants return to the village from the brick kilns in May and leave the village in 
Table 1 Area of residence and age-wise attack rates (incidence proportion) of kala-azar in Kosra village, stratified by gender (70 cases)

\begin{tabular}{|c|c|c|c|c|c|c|}
\hline \multirow[t]{2}{*}{ Characteristics } & \multicolumn{2}{|l|}{ Male } & \multicolumn{2}{|l|}{ Female } & \multicolumn{2}{|l|}{ Total } \\
\hline & $\begin{array}{l}\text { No. of VL/ Population in } \\
\text { group }\end{array}$ & $\begin{array}{l}\text { Attack rate } \\
(\%)\end{array}$ & $\begin{array}{l}\text { No. of VL/ population in } \\
\text { group }\end{array}$ & $\begin{array}{l}\text { Attack rate } \\
(\%)\end{array}$ & $\begin{array}{l}\text { No. of VL/ population } \\
\text { group }\end{array}$ & $\begin{array}{l}\text { Attack rate } \\
(\%)\end{array}$ \\
\hline \multicolumn{7}{|l|}{ Area of residence } \\
\hline $\begin{array}{l}\text { Southern hamlet and its } \\
\text { extension }\end{array}$ & $39 / 158$ & 24.7 & $24 / 174$ & 13.8 & $63 / 332$ & 19.0 \\
\hline Rest of the village & 4/ 759 & 0.5 & 3/ 667 & 0.4 & 7/ 1426 & 0.5 \\
\hline \multicolumn{7}{|l|}{ Age group* } \\
\hline $0-14$ & $14 / 365$ & 3.8 & $9 / 320$ & 2.8 & $23 / 685$ & 3.4 \\
\hline $15-29$ & $12 / 199$ & 6.0 & $9 / 232$ & 3.9 & $21 / 431$ & 4.9 \\
\hline $30-44$ & $10 / 153$ & 6.5 & $3 / 137$ & 2.2 & $13 / 290$ & 4.5 \\
\hline $45-59$ & $3 / 98$ & 4.1 & $4 / 90$ & 4.4 & 7/ 188 & 3.7 \\
\hline $60+$ & $4 / 102$ & 3.9 & $2 / 62$ & 3.2 & 6/ 164 & 3.7 \\
\hline Total & $43 / 917$ & 4.7 & 27/841 & 3.2 & $70 / 1758$ & 4.0 \\
\hline
\end{tabular}

Since gender details of 9 enumerated individuals were missing, denominator is 1758 instead of 1767 . ${ }^{*}$ For age-group, $\mathrm{Chi}-\mathrm{square}=1.86$, df $=4, p=0.762$. VL Visceral leishmaniasis (kala-azar)

October, thereby staying in the village during the prewinter peak transmission period [16, 21].

Cases informed that contractors visit the southern hamlet of the village and lend sums of Rs 25,000-30,000 (USD 350-400) per labourer in advance to the families under an informal agreement to work in brick kilns. The sum received is used to pay back loans taken from local money lenders at high interest rates. Out of pocket medical expenditure are a major reason for taking these loans. This creates a self-perpetuating cycle of social exclusion, indebtedness, poverty and malnutrition for the migrants $[19,20]$.

\section{Verbal autopsy findings}

Four children and one adult had died after 2-6 months of prolonged irregular fever, weakness, loss of appetite and pronounced abdominal swelling (only for children) in the most affected southern hamlet of the village. Blackish discoloration of skin was noted in the adult who died. Both genders were affected. The deaths happened between October 2016 - March 2017 before any diagnosis of kala-azar could be attempted. All five deaths could be epidemiologically linked to a family member or an immediate neighbour having been confirmed with kala-azar within 6 months of their death.

\section{Coverage of IRS and entomological study}

Regular IRS round was done covering all the houses of the village -during 20-26 March 2017 and 26-31 August 2017. Focal spray was conducted in clusters of 70 200 houses around reported kala-azar cases in the southern hamlet during 15-17 May 2017, on 8 July 2017, 2527 July 2017 and 20-22 December 2017.
Only half the dwellings of the kala-azar cases had been found to be fully sprayed during the most recent IRS conducted in May 2017 (Table 2). This was found to be inadequate as per norm of $80 \%$ coverage of household units $[4,22]$.

$P$. argentipes were collected from most of the households in the southern hamlet which had been sprayed thrice during the preceding four months. No other phlebotomine species were found. Six female $P$. argentipes were found to be fully gravid (Table 3). Mortality on mud and brick surfaces was below the recommended 80\% level (Table 3) [22].

\section{Discussion}

The intense spatial and temporal clustering of cases in the southern hamlet merits association with the index case. The long duration of untreated kala-azar in the index case would have sustained parasite transmission to sandflies present in the favourable eco-environmental setting of the village. Consequently, migrants residing in the village during the pre-winter transmission period would have been infected [21]. Subsequent development of fever in early part of 2017 nearly matches the average incubation period estimate of 4-6 months to 1 year [6, 23].

Clustering of kala-azar cases at meso-scale level has been reported in studies from Vaishali district, India and Dharan, Nepal $[24,25]$. The present study uniquely reports an intense clustering even within a hamlet level at a scale of within $100 \mathrm{~m}$. This is known to be partly due to the short flight range and enhanced transmission efficiency of the infected $P$. argentipes vector through biting persistence and multi-host feeding [26, 27]. 
Table 2 Health seeking behaviour, access to diagnosis, treatment and preventive services and risk factors for kala-azar ( $n=50$ kalaazar patients, unless stated otherwise)

\begin{tabular}{ll}
\hline Characteristics & $\mathrm{N}$ \\
\hline Health seeking behaviour and access to services & $\%$ \\
Type of health facility where care was first sought for fever & 18 \\
Government PHC/ Government District hospital & 19 \\
Quack (unqualified practitioner) & 6 \\
Private qualified physician & 6 \\
Didn't contact anyone (found first on active case search) & 36
\end{tabular}

Type of first health facility contact in context of migration

With migration

Without migration

Place of diagnosis of kala-azar

District hospital

In village during active case search

Others (private facility)

Person who motivated to get tested for kala-azar

ASHA (Accredited Social Health Activist)

ANM (Auxiliary Nursing Midwife)

Self

Another community member

Received monetary incentive $(n=45)$

Focal spray conducted within 2 weeks of fever onset

Quality of spray in preceding focal IRS of May $2017(n=42)$

All rooms and animal shelter(s) spayed

One or more rooms or animal shelter(s) missed

Awareness

Awareness regarding mode of spread of Kala-azar

Through sandfly bite

Through mosquito bite

Through dirty water

Directly from infected person

Awareness regarding duration for which walls should not be smeared or painted after IRS

More than 90 days

Less than 60 days

Don't know

Having awareness that animal shelter spraying is necessary for kala-azar prevention

Risk factors for kala-azar

Illiteracy 
Table 2 Health seeking behaviour, access to diagnosis, treatment and preventive services and risk factors for kala-azar ( $n=50$ kalaazar patients, unless stated otherwise) (Continued)

\begin{tabular}{lll}
\hline Characteristics & $\mathrm{N}$ & \multicolumn{1}{c}{$\%$} \\
\hline Poverty (Per capita income per month < Rs 1000) & 43 & 32 \\
Domestic animal ownership & 16 & 7 \\
Animal shelter location within house & 26 & 52 \\
Residing in thatched mud house without windows (kutcha house) & 45 \\
Sleeping in room with unplastered walls & 24 \\
Sleeping on floor & 40 \\
Non-use of mosquito net & 40 \\
\hline
\end{tabular}

All age-groups being similarly affected with kala-azar suggests an outbreak in non-endemic or low-endemic setting which is unlike an outbreak in endemic settings wherein older age groups are less affected as a result of immunity acquired from past infection [28]. Poverty, dietary changes and subsequent malnutrition associated with migration might have acted as risk factors for kalaazar infection, through weakening of host immunity [29-31]. A study in Bangladesh found low serum zinc and retinol levels as predisposing to conversion from asymptomatic infection to clinical case [32]. Zinc is essential for cell-mediated immunity which is responsible for resistance to Leishmania donovani infection $[33,34]$. Therefore, host micronutrient status has been proposed as a potential risk factor for leishmania infection in Bihar [29].

\section{Role of seasonal migration}

Majority of cases in the present outbreak developed symptoms while they were still working in the brick kilns located in different parts of the country and got treated on return to their village. Poor access to health care and low index of suspicion of kala-azar in these non-endemic areas and the low-endemic area back home resulted in patients spending considerable time and money without proper treatment. Migration was also suggested to play a role in kala-azar outbreaks in Dharan in Nepal, Varanasi in India and among Somali refugees and Kenyan shepherds in Africa [25, 35, 36]. However, in the present outbreak, migration to brick kilns doesn't appear to have played a role in kala-azar transmission to the migrants per se. Rather it probably emerged as a risk-factor for development of kala-azar disease owing to poor nutrition and stress and also contributed to delayed diagnosis and treatment.

Finally, given the presence of $P$. argentipes vector over large areas of Indian sub-continent, there is hazard of establishment of transmission in far-flung non-endemic areas [21]. This could be possible if the brick kilns employing migrants from kala-azar endemic areas have presence of $P$. argentipes vector and are close to permanent human settlements located within the vector's flight range [26]. Although high vector density at brick kilns could be less likely due to the unique requirement of damp, organic rich conditions for their oviposition and breeding [37], this needs entomological exploration at those brick kilns with seasonal migration from kala-azar endemic districts.

\section{Kala-azar transmission after outbreak response}

Following the outbreak response in June 2017, approximately one kala-azar case was being reported per month (Fig. 5). Also, we found that 8 of the 352 rK39seronegatives found during the outbreak response were subsequently diagnosed with kala-azar and were treated for it (Fig. 3). Most of these individuals would have either been incubating or would have been asymptomatic during the outbreak response. Further, with four additional kala-azar cases being reported from the village in 2019 with the most recent case in September 2019 i.e. more than twice the average incubation period after the outbreak response, it appears that kala-azar transmission couldn't be completely interrupted in the village [23].

Dwellings of only half the kala-azar cases had been fully sprayed. Entomological findings pointed towards ineffective vector control during the outbreak. Resistance of vectors to Alpha-Cypermethrin insecticide could be ruled out as a reason for the bio-assay result since the affected area had been exposed to this insecticide only thrice prior to the assay. Cross-resistance with Dichlorodiphenyltrichloroethane (DDT) also could be ruled out as the village had no prior exposure to DDT for IRS (for either kala-azar or malaria) in the past 10 years. Thus, bioassay findings could be mainly explained by underdosing of insecticide residue on walls in the three preceding IRS. Under-dosing could have been due to one or more of the following factors - patchy coverage of sprayable surfaces, less than recommended quantity of insecticide being used for suspension preparation, improper spray technique resulting in wider swath or faster spraying or due to less than recommended active 


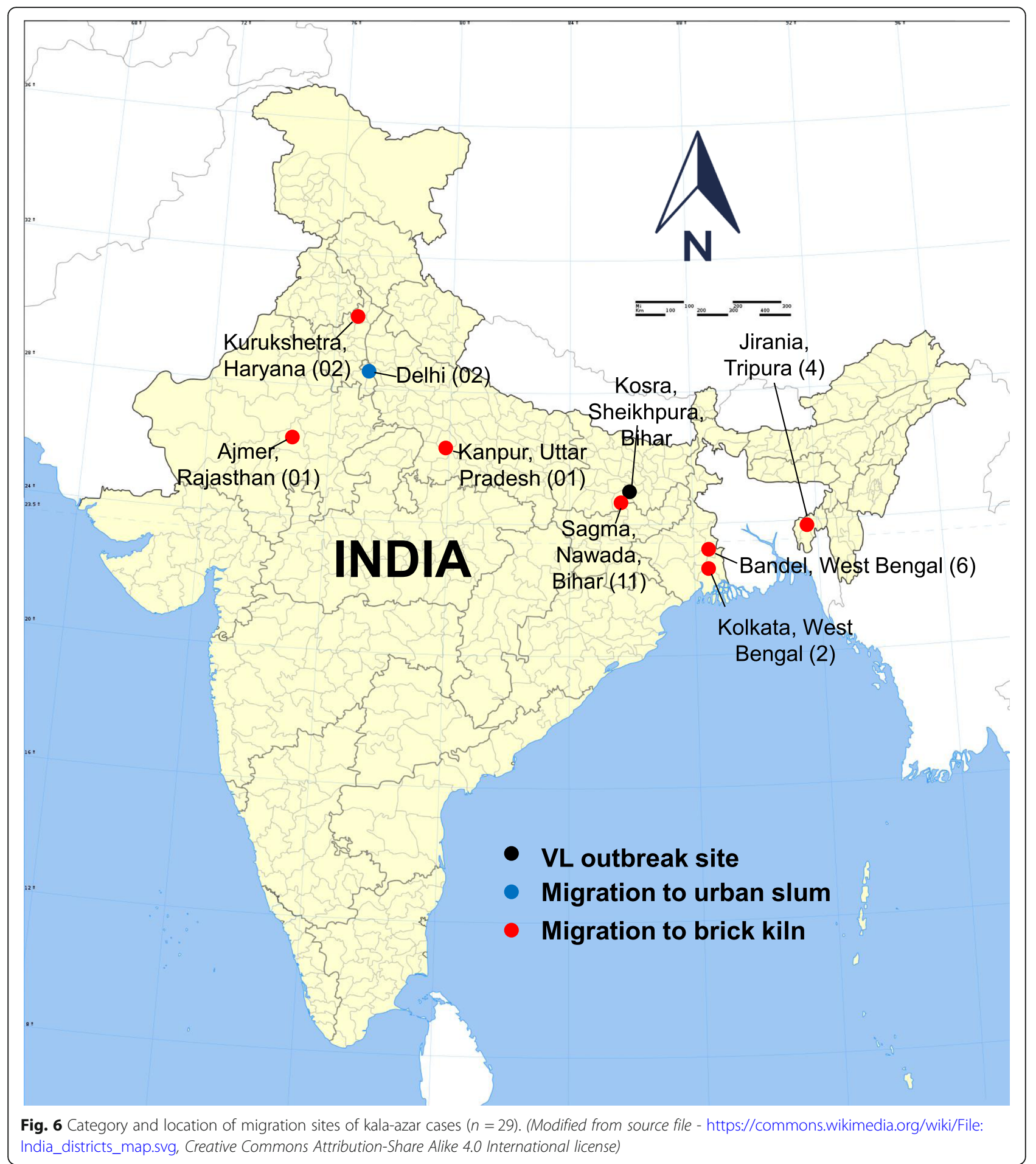

ingredient concentration in the insecticide supplied [38]. We couldn't assess all these factors in the present study.

In August 2018, the district programme was officially notified regarding 61 batches of Alpha-Cypermethrin wettable powder insecticide which had failed the recommended active ingredient specifications [39]. One of these failed batches of insecticide had been used in the affected village for the IRS rounds conducted in 2017. This could also help retrospectively explain the ineffective vector control leading to persistence of transmission in the present outbreak.

During the outbreak response, rk39-positive individuals providing history of fever without palpable spleen finding were not considered for treatment, as per 
Table 3 Entomological findings in the southern hamlet of the affected village

\begin{tabular}{lll}
\hline Characteristics & $\mathrm{n} /$ total & $\%$ \\
\hline P. argentipes density using mouth aspirator & & \\
$\quad$ Households found positive for sandfly & $28 / 34$ & 82.4 \\
$\quad$ Female percentage & $14 / 37$ & 37.8 \\
$\begin{array}{l}\text { P. argentipes density using CDC light trap } \\
\quad \text { Households found positive for sandfly }\end{array}$ & $8 / 8$ & 100 \\
$\quad$ Female percentage & $10 / 25$ & 40.0 \\
Cone bio-assay & & \\
Mud surface ( $n=7$ surfaces) & & \\
$\quad$ Knockdown & $82 / 136$ & 60.3 \\
$\quad$ Mortality ( $24 \mathrm{~h}$ ) & $107 / 136$ & 78.7 \\
Brick surface ( $n=3$ surfaces) & & 50.0 \\
$\quad$ Knockdown & $30 / 60$ & 61.7 \\
$\quad$ Mortality ( $24 \mathrm{~h}$ ) & $37 / 60$ & \\
\hline Bioassay control: $0 \%$ mortality & &
\end{tabular}

programme guidelines [11]. Also, since fever is initially low-grade and intermittent in kala-azar, this symptom might not always be confirmed clinically. Spleen becomes palpable only after being enlarged twice to thrice [40]. Therefore, transmission potential of such cases should also be considered [41, 42]. Ultrasonographic detection of sub-palpable splenomegaly and bone marrow/ intercostal splenic parasitology has been found to provide additional yield of kala-azar cases [43]. These should be explored, especially in outbreak settings. Findings of the present study could be generalizable to low-endemic and previously high-endemic areas for kala-azar in the Indian sub-continent.

\section{Limitations and sources of potential bias}

Due to the insidious onset and prolonged fever seen in kala-azar, recall bias could have crept in while assessing duration of fever preceding kala-azar diagnosis.

\section{Conclusions}

The interruption of transmission in outbreaks must rely on both complete case finding and effective vector control. This could be achieved through coverage of all sprayable surfaces during IRS and use of insecticide compliant with quality norms and plastering the walls of mud houses. Kala-azar, a neglected tropical disease, was found to disproportionately affect the poor and marginalized community.

This outbreak revealed the need to strengthen kalaazar elimination programme especially in low endemic and migratory settings so that future kala-azar outbreaks could be prevented and detected early. For example, establishment of routine framework for kala-azar outbreak response is needed owing to risk of outbreaks in low- endemic areas and areas which have hitherto achieved elimination targets [44].

There is scope for further reduction of delay between fever onset and diagnosis through sensitization of government and private practitioners, frontline health workers and active case detection, especially in migratory settings. Reduction of this delay has the potential to not only reduce out-of-pocket medical expenditure, but also to prevent future outbreaks and lead to dramatic reduction of kala-azar incidence in Bihar, India [45].

\section{Abbreviations}

CDC: Centers for Disease Control and Prevention, Atlanta, USA;

DDT: Dichlorodiphenyltrichloroethane; DVBDCO: District vector borne disease control officer; ICMR: Indian Council of Medical Research; IQR: Interquartile range; IRS: Indoor residual spraying; LAmB: Liposomal amphotericin B; NVBDCP: National vector borne disease control programme; RMRIMS: Rajendra Memorial Research Institute of Medical Sciences, Patna, India; VL: Visceral leishmaniasis; WHO: World Health Organization

\section{Acknowledgements}

Firstly, we would like to acknowledge Dr. Saurabh Jain, Scientist Global Leishmaniasis Programme, WHO- Headquarters for his technical guidance. He was National Professional officer -Neglected Tropical Diseases (NTD) with WHO India when the study was initiated. Contractors with neglected tropical diseases department of World Health Organization India provided technical support for the study. We would like to thank Dr. Manoj Kumar Singh, Zonal Coordinator NTD, Ranchi, India for his help provided in data collection. Mr. Vikas Kumar, block co-ordinator with Care India is acknowledged for the logistical support provided by him. Team from RMRIMS, Patna, Bihar are acknowledged for their help provided in entomological study. We thank field level health workers Ms. Usha Sinha, Ms. Dharamshila Devi, Ms. Kavita Devi, Ms. Saroj Manju, Ms. Paramshila Devi, Ms. Sita Devi and Ms. Babita Kumari who participated in the house-to-house case search.

\section{Authors' contributions}

AK conceived the study and provided technical inputs. SS developed the study protocol and formats, conducted data analysis and wrote the manuscript and both SS and SJ conducted data collection, data entry and literature search. VK conducted the entomological investigation. All the authors reviewed and approved the manuscript.

\section{Funding}

The authors declare that no funding was received from any source for the study and preparation of this article.

\section{Availability of data and materials}

All data related to the study belongs to the District Health SocietySheikhpura, Government of Bihar, India. Data is not being publicly shared due to potential identifiability of study participants in a small community, even after anonymization. Those interested to obtain the data may contact the District Vector Borne Disease Control Office, Sheikhpura with a statement of purpose atvbdspura@gmail.com

\section{Ethics approval and consent to participate}

The study was done as part of an urgently needed outbreak response and programme evaluation study with the purpose of improvement of the national kala-azar elimination programme. Therefore, it was considered exempt from review by institutional ethics committee as guided by the ICMR National Ethical Guidelines for Biomedical and Health Research involving $\mathrm{Hu}-$ man Participants 2017. The study was conducted in accordance with the national ethical guidelines and a certificate to this effect was provided by chief medical officer of Sheikhpura district. Verbal informed consent was taken from all participants of the study including the index case, in the presence of two witnesses. Informed consent was obtained from a parent or guardian for those participants less than 16 years of age. Verbal informed consent method was adopted due to overwhelming majority of study participants not being literate. Due to the urgent nature of the outbreak investigation, approval of 
this verbal informed consent procedure could not be sought from ethics committee.

\section{Consent for publication}

Not applicable.

\section{Competing interests}

The authors declare that there is no competing interest for publication of this article. The views expressed in this article are those of the authors alone and do not necessarily represent the views of their respective organizations.

\section{Author details}

${ }^{1}$ Vector Borne Diseases Control officer - Sheikhpura district, Health Department, Government of Bihar, India. Currently, Chief Medical Officer Arwal district, Health Department, Government of Bihar, Sheikhpura, India. ${ }^{2}$ Zonal Coordinator - Neglected Tropical Diseases, Muzaffarpur, World Health Organization - India. Currently, Assistant Professor, Department of Community and Family Medicine, All India Institute of Medical Sciences (AlIMS) - Jodhpur, Jodhpur, Rajasthan 342005, India. ${ }^{3}$ Zonal Coordinator Neglected Tropical Diseases, Bhagalpur, World Health Organization - India. Currently, State Coordinator - Neglected Tropical Diseases, World Health Organization - India, Raipur, Chhattisgarh, India. ${ }^{4}$ Consultant and Ex-Scientist E, Department of Vector Biology \& Control, Rajendra Memorial Research Institute of Medical Sciences (Indian Council of Medical Research), Patna, India.

Received: 2 April 2019 Accepted: 22 December 2019 Published online: 06 January 2020

\section{References}

1. Farrar J, Hotez P, Jughanss T, Kang G, Lalloo D, White NJ. Manson's tropical diseases: expert consult - online and print, 23e. 23 edition. Edinburgh: Saunders Ltd.; 2013.

2. World Health Organization. Process of validation of elimination of kala-azar as a public health problem in South-East Asia. New Delhi: World Health Organization South East Asia Regional Office (SEARO); 2016. http://www. who.int/leishmaniasis/resources/Process_of_validation_of_VL_elimination_ SEA_CD_321.pdf?ua=1\&ua=1 (accessed December 2019)

3. Directorate of National Vector Borne Diseases Control Programme Kala-azar cases and deaths in the country since 2010. Ministry of Health and Family Welfare, government of India, New Delhi; 2018.

4. Directorate of National Vector Borne Diseases Control Programme of India, New Delhi. Operational Guidelines for Kala-azar (Visceral Leishmaniasis) Elimination in India. New Delhi: Ministry of Health and Family Welfare, Government of India; 2015.

5. World Health Organization. Regional Strategic Framework for elimination of Kala-azar from South-East Asia Region 2011-2015. New Delhi, World Health Organization South East Asia Regional Office (SEARO), 2012.

6. Bora D. Epidemiology of visceral leishmaniasis in India. Natl Med J India. 1999;12:62-8.

7. Burza S, Croft SL, Boelaert M. Leishmaniasis. Lancet. 2018:392:951-70. https:// doi.org/10.1016/S0140-6736(18)31204-2.

8. Stauch A, Sarkar RR, Picado A, Ostyn B, Sundar S, Rijal S, et al. Visceral leishmaniasis in the Indian subcontinent: modelling epidemiology and control. PLoS Negl Trop Dis. 2011;5:e1405. https://doi.org/10.1371/journal. pntd.0001405.

9. Mandal R, Kesari S, Kumar V, Das P. Trends in spatio-temporal dynamics of visceral leishmaniasis cases in a highly-endemic focus of Bihar, India: an investigation based on GIS tools Parasit Vectors. 2018;11:220. https://doi.org/ 10.1186/s13071-018-2707-x

10. Ostyn B, Uranw S, Bhattarai NR, Das ML, Rai K, Tersago K, et al. Transmission of Leishmania donovani in the hills of eastern Nepal, an outbreak investigation in Okhaldhunga and Bhojpur districts. PLoS Negl Trop Dis. 2015;9:e0003966. https://doi.org/10.1371/journal.pntd.0003966.

11. Directorate of National Vector Borne Disease Control Programme. Accelerated Plan for Kala-azar Elimination 2017. Ministry of Health and Family Welfare, government of India, New Delhi; 2017.

12. Indian Council of Medical Research (Department of Health Research). National Ethical Guidelines for Biomedical and Health Research involving Human Participants 2017. New Delhi: Ministry of health and family welfare, government of India; 2017. https://icmr.nic.in/sites/default/files/guidelines/ ICMR_Ethical_Guidelines_2017.pdf (accessed December 2019)

13. Lewis DJ. A taxonomic review of the genus phlebotomus (Diptera: Psychodidae). Bull Br Mus Nat Hist. 1982;45:121-209.

14. World Health Organization. Test procedures for insecticide resistance monitoring in malaria vector mosquitoes $2^{\text {nd }}$ Ed. Geneva: World Health Organization; 2016. https://apps.who.int/iris/rest/bitstreams/1063682/retrieve (accessed December 2019)

15. World Health Organization. Instructions for determining the susceptibility or resistance of adults blackflies, sandflies and biting midges to insecticides. Geneva: WHO; 1981

16. Bhunia GS, Kumar $V$, Kumar AJ, Das P, Kesari S. The use of remote sensing in the identification of the eco-environmental factors associated with the risk of human visceral leishmaniasis (kala-azar) on the Gangetic plain, in NorthEastern India. Ann Trop Med Parasitol. 2010;104:35-53. https://doi.org/10. 1179/136485910X12607012373678.

17. Bhunia GS, Kesari S, Jeyaram A, Kumar V, Das P. Influence of topography on the endemicity of Kala-azar: a study based on remote sensing and geographical information system. Geospat Health. 2010;4:155-65. https:// doi.org/10.4081/gh.2010.197.

18. Bhunia GS, Kesari S, Chatterjee N, Pal DK, Kumar V, Ranjan A, et al. Incidence of visceral leishmaniasis in the Vaishali district of Bihar, India: spatial patterns and role of inland water bodies. Geospat Health. 2011;5:205-15. https://doi. org/10.4081/gh.2011.173.

19. Kumar N, Sidhu AS. Pull and push factors in labour migration: a study of brick-kiln Workers in Punjab. Indian J Ind Relat. 2005;41:221-32.

20. Kainth GS. Push and pull factors of migration: a case study of brick kiln migrant Workers in Punjab. Munich Personal RePEc Archive. 2010; https:// mpra.ub.uni-muenchen.de/30036/ (accessed December 2019).

21. Chowdhury R, Kumar V, Mondal D, Das ML, Das P, Dash AP, et al. Implication of vector characteristics of Phlebotomus argentipes in the kalaazar elimination programme in the Indian sub-continent. Pathog Glob Health. 2016;110:87-96. https://doi.org/10.1080/20477724.2016.1180775.

22. World Health Organization. Indicators for monitoring and evaluation of the kala-azar elimination programme. World Health Organization South East Asia Regional Office, New Delhi; 2010. Available from: http://www.who.int tdr/publications/documents/kala_azar_indicators.pdf (accessed December 2019).

23. Hossian M, Jamil KM. Pathology and mechanism of disease in Kala-azar and post Kala-azar dermal leishmaniasis. In: Jha TK, Noiri E, editors. Kala Azar in South Asia: current status and challenges ahead. 2nd ed. Dordrecht: Springer Netherlands; 2011. p. 11-4.

24. Bhunia GS, Kesari S, Chatterjee N, Kumar V, Das P. Spatial and temporal variation and hotspot detection of kala-azar disease in Vaishali district (Bihar). India BMC Infect Dis. 2013;13:64. https://doi.org/10.1186/1471-233413-64.

25. Uranw S, Hasker E, Roy L, Meheus F, Das ML, Bhattarai NR, et al. An outbreak investigation of visceral leishmaniasis among residents of Dharan town, eastern Nepal, evidence for urban transmission of Leishmania donovani. BMC Infect Dis. 2013;13:21. https://doi.org/10.1186/1471-2334-13-21.

26. Mutinga MJ, Kamau CC, Basimike M, Mutero CM, Kyai FM. Studies on the epidemiology of leishmaniasis in Kenya: flight range of phlebotomine sandflies in Marigat. Baringo District East Afr Med J. 1992;69:9-13.

27. Rogers ME, Bates PA. Leishmania manipulation of sandfly feeding behavior results in enhanced transmission. PLoS Pathog. 2007:3:e91. https://doi.org/ 10.1371/journal.ppat.0030091.

28. Detels R, Beaglehole R, Lansang MA, Gulliford M. Oxford textbook of public health. 5 edition. Oxford. New York: OUP UK; 2011.

29. Das S, Matlashewski G, Bhunia GS, Kesari S, Das P. Asymptomatic Leishmania infections in northern India: a threat for the elimination programme? Trans R Soc Trop Med Hyg. 2014;108:679-84. https://doi.org/10.1093/trstmh/ tru146.

30. Choudhary N, Parthasarathy D. Is migration status a determinant of urban nutrition insecurity? Empirical evidence from Mumbai city. India J Biosoc Sci. 2009;41:583-605. https://doi.org/10.1017/S002193200900340X.

31. Picado A, Ostyn B, Singh SP, Uranw S, Hasker E, Rijal S, et al. Risk factors for visceral leishmaniasis and asymptomatic Leishmania donovani infection in India and Nepal. PLoS One. 2014;9:e87641. https://doi.org/10.1371/journal. pone.0087641.

32. Bern C, Haque R, Chowdhury R, Ali M, Kurkjian KM, Vaz L, et al. The epidemiology of visceral leishmaniasis and asymptomatic leishmanial 
infection in a highly endemic Bangladeshi village. Am J Trop Med Hyg. 2007;76:909-14.

33. Prasad AS. Zinc in human health: effect of zinc on immune cells. Mol Med. 2008;14:353-7. https://doi.org/10.2119/2008-00033.

34. Singh OP, Gidwani $K$, Kumar R, Nylén $S$, Jones SL, Boelaert M, et al. Reassessment of immune correlates in human visceral leishmaniasis as defined by cytokine release in whole blood. Clin Vaccine Immunol. 2012;19: 961-6. https://doi.org/10.1128/CVI.00143-12.

35. Kumar R, Kumar P, Chowdhary RK, Pai K, Mishra CP, Kumar K, et al. Kala-azar epidemic in Varanasi district. India Bull World Health Organ. 1999;77:371-4.

36. Boussery G, Boelaert M, van Peteghem J, Ejikon P, Henckaerts K. Visceral leishmaniasis (kala-azar) outbreak in Somali refugees and Kenyan shepherds. Kenya Emerg Infect Dis. 2001;7:603-4. https://doi.org/10.3201/eid0707. 010746

37. Kumar V, Rama A, Kesari S, Bhunia GS, Dinesh DS, Das P. Oviposition behaviour of Phlebotomus argentipes--a laboratory-based study. Mem Inst Oswaldo Cruz. 2013;108:1065-7. https://doi.org/10.1590/0074-0276130003.

38. World Health Organization. Indoor Residual Spraying: an operational manual for indoor residual spraying (IRS) for malaria transmission control and elimination - 2nd ed. World Health Organization, Geneva; 2015. Available at: http://apps.who.int/iris/bitstream/10665/177242/1/9789241508940_eng. pdf?ua=1\&ua=1 (accessed December 2019).

39. World Health Organization. WHO Specifications and Evaluations for Public Health Pesticides: Alpha-Cypermethrin. Geneva, World Health Organization, 2015. Available at: https://www.who.int/neglected_diseases/vector_ecology/ pesticide-specifications/en/Alphacypermethrin_WHO_specs_eval_Feb_2015. pdf (accessed December 2019).

40. Kumar L, Bansal AK. Splenomegaly - a clinical approach. In: Munjal YP, Sharma SK, editors. API textbook of medicine. 9th ed. New Delhi: Jaypee Brothers Medical Publishers; 2012. p. 926-7.

41. Hirve S, Boelaert M, Matlashewski G, Mondal D, Arana B, Kroeger A, et al. Transmission dynamics of visceral Leishmaniasis in the Indian subcontinent - a systematic literature review. PLoS Negl Trop Dis. 2016;10:e0004896. https://doi.org/10.1371/journal.pntd.0004896.

42. Le Rutte EA, Coffeng LE, Bontje DM, Hasker EC, Ruiz Postigo JA, Argaw D, et al. Feasibility of eliminating visceral leishmaniasis from the Indian subcontinent: explorations with a set of deterministic age-structured transmission models. Parasit Vectors. 2016;9. https://doi.org/10.1186/s13071016-1292-0.

43. Thakur CP. A comparison of intercostal and abdominal routes of splenic aspiration and bone marrow aspiration in the diagnosis of visceral leishmaniasis. Trans R Soc Trop Med Hyg. 1997;91:668-70.

44. Le Rutte EA, Chapman LAC, Coffeng LE, Ruiz-Postigo JA, Olliaro PL, Adams $E R$, et al. Policy recommendations from transmission modeling for the elimination of visceral Leishmaniasis in the Indian subcontinent. Clin Infect Dis. 2018;66:S301-8. https://doi.org/10.1093/cid/ciy007.

45. Medley GF, Hollingsworth TD, Olliaro PL, Adams ER. Health-seeking behaviour, diagnostics and transmission dynamics in the control of visceral leishmaniasis in the Indian subcontinent. Nature. 2015;528:S102-8. https:// doi.org/10.1038/nature16042.

\section{Publisher's Note}

Springer Nature remains neutral with regard to jurisdictional claims in published maps and institutional affiliations.

Ready to submit your research? Choose BMC and benefit from:
- fast, convenient online submission
- thorough peer review by experienced researchers in your field
- rapid publication on acceptance
- support for research data, including large and complex data types
- gold Open Access which fosters wider collaboration and increased citations
- maximum visibility for your research: over 100M website views per year
At BMC, research is always in progress.
Learn more biomedcentral.com/submissions

